\title{
Practices regarding colostrums and pre-lacteals among gadaba and konda dora tribes of vizianagaram district
}

\author{
Giridhar $\mathrm{L}^{1}$ and Lakshmi $\mathrm{G}^{2}$ \\ ${ }^{1-2}$ Senior Research fellow, Department of Anthropology, Andhra University, Visakhapatnam-530003.
}

\begin{abstract}
Feeding of breast milk is the first fundamental right of the child. Some believe pre-lacteals are a necessary substitute for colostrums. The practice of giving pre-lacteal feed to baby is a traditionally accepted culture in India. A cross-sectional study was conducted on Gadaba and Konda Dora tribal populations at random from 95 tribal villages in Vizianagaram district of Andhra Pradesh. Data were collected from 300 lactating women from each tribe, age ranges between 15-45 years through in-depth interview method. The practice of discarding of colostrums (the first breast milk) is still exists among Gadaba (25.7\%) than Konda Dora (20.0\%). Because of the late initiation of the breast milk, the newborns were fed with pre-lacteal foods (27.3\% of Gadaba and 22.7\% of Konda Dora newborns). They are feeding the newborns with pre-lacteals in a most unhygienic method i.e. by using either finger or spoon or cotton. The deep-rooted traditional beliefs and misconceptions are observed in discarding of colostrums and introducing the pre-lacteals to their babies. Proper knowledge should be given to the mothers regarding the importance of colostrums and effects of pre-lacteal feedings.
\end{abstract}

Keywords_Breast milk, Colostrums, Pre-lacteals, Traditional beliefs

\section{INTRODUCTION}

As per the recommendation of UNICEF (2011), breast feeding should be initiated within a half-hour of birth instead of waiting several hours as is often customary. Although there is a little milk at that time, it helps to establish feeding and a close mother-child relationship, known as "bonding". The first milk, i.e. the "colostrums" is the most suitable food for the baby immediately after birth because it contains a high concentration of protein and other nutrient to the body needs; it is also rich in anti-infective factors which protect the baby against respiratory infections and diarrhoeal diseases. Some believe pre-lacteals are a necessary substitute for colostrums. Pre-lacteal feeds are foods given to newborns before breastfeeding is established or before breast milk "comes in," usually on the first day of life (UNICEF, 2008).

\section{MATERIALS AND METHODS}

The present study was conducted in a tribal area of Andhra Pradesh to assess the proportion of home deliveries, to identify the different categories of care providers and to find out the prevailing traditional practices regarding some essential components of cord care. For the present study, 600 respondents (both tribes), age ranges from 15 to 45 years from lactating women belonging to Gadaba and Konda Dora tribal women were selected at random from 95 villages of Vizianagaram District. Systematic random sampling was followed in selecting the stake-holders from the tribal areas and the statistical analysis was done by using SPSS 11.0 package.

\section{RESULTS AND DISCUSION}

About $87.3 \%$ of Gadaba and $85.3 \%$ of Konda Dora newborns were initiated with mother's milk within 2-6 hours after delivery. The mean duration of exclusive breast feeding is more among Konda Doras (7.05 months) than the infants of Gadabas (6.52). Similarly the mean duration of lactation is very lengthy among the Konda Doras i.e. 34.85 months against 24.68 months among the children of Gadaba tribe. The duration of lactation among the children of Konda Dora and Gadaba tribal groups is extending upto 24-35 months and is a common phenomenon found in many of the neighbouring tribal populations.

Nearly $26.0 \%$ of the Gadaba and $20.0 \%$ of Konda Dora women are discarding the colostrums but not in total (Table-1 and Fig-1). Nearly $23.0 \%$ of the newborns who were initiated with mother's milk with in the first hour after birth were also deprived of 1-2 Table spoons of colostrums. If the initiation of breast milk was done with in 1 hour after birth, discarding of colostrums was to a maximum of 1-2 times. In the 7-12 hours and 12-48 hours, the frequency of discarding of colostrums was extended up to a maximum of 5 times. 
The NFHS-2 (1998-99) surveyed in four states of India found that the breast feeding is a universal phenomenon among the tribal women, but they discarded the colostrums. Further the data compiled by NFHS-2 (1998-99) also gave a high incidence of discarding colostrums in both the rural and urban areas in India. Durga Rao, et.al., (2006) studied the tribes of North Coastal Andhra Pradesh tribes and revealed that nearly 16.0\% of mothers have discarded the colostrums before the child was fed with breast milk. Nearly $17.0 \%$ of the mothers from slum areas of Visakhapatnam (Swamy, 2009) have discarded the colostrums before the initiation of the mothers' milk. The Visakhapatnam tribals also have the practice of discarding the colostrums $(42.0 \%)$ instead feeding to their newborns (Sambasiva Rao, 2008a). Further he stated that about 25.0\% of mothers have discarded the colostrums 1-3 times before initiating the breast milk to their newborns. The other two studies, one on Savara of Srikakulam district (Narahari, et.al., 2006) and Gadaba tribe of Vizianagaram district (Hemalatha, 2005 ) revealed that nearly $80.0 \%$ and $72.0 \%$ of the mothers discarded the colostrums, respectively. But very less percentage $(20.0 \%)$ of mothers discarding the colostrums as reported by Nanibabu, et.al., (2006) among the Koya Dora tribe of East Godavari district. The study carried out by Mudgal, et.al., (1979) in Madhya Pradesh, the tribal women have not discarded the colostrums and were given to their newborns. Similarly, Pandey, et.al., (1997) reported that the colostrums was not discarded among the Hill Korwa and Pando tribes of Madhya Pradesh and the tribes of Gujarat (Gopaldas and Gujral, 1995). Even the Bhumija women of Orissa (35.1\%) have not discarded the colostrums as reported by Goswamy (2009).

Many reasons are responsible for the discarding of colostrums as revealed by many respondents. The main reasons for discarding the colostrums (partial) are- not good for the child (38.5\% of Gadabas and $37.9 \%$ of Konda Doras), advice of elders (32.1\% of Gadaba and 24.1\% of Konda Doras), and traditional belief (19.2\% of Gadabas and $24.1 \%$ of Konda Doras). The other reasons reported by them are not pure $(8.1 \%)$, stagnant $(2.2 \%)$ and heavy to digest $(1.5 \%)$.

In contrary from the present study, the tribal women of Vizianagaram (Sambasiva Rao, 2008) have discarded the colostrums relatively lesser (25.0\%). The rural Ghana women $(74.8 \%)$ have realized the importance of colostrums and offered to their newborn; whereas $25.2 \%$ of mothers discarded the colostrums for one $(47.2 \%)$ time or two times $(30.5 \%)$ or three times $(20.8 \%)$ before the initiation of first mothers milk. The main reasons for discarding the first milk (colostrums) given by the mothers were, they got advice from elders $(42.2 \%)$, not pure $(9.1 \%)$, not good for child $(8.8 \%)$, stagnant $(7.0 \%)$ and heavy $(4.7 \%)$ (Karen, et.al., 2006). Family restrictions $(30.2 \%)$, followed by social customs $(25.6 \%)$ were the main reasons for discarding colostrums reported by Durga Rao, et.al., (2006) among the tribes of North Coastal Andhra Pradesh. Khan and Basu (1987) conducted a study among the women of un-organized sector and reported that social customs or advice from the elderly women of the family is the main reasons for the discarding of the colostrums. The tribal women of Jharkhand (Banerjee and Mishra, 2006) do not initiate the breast milk before the third day and they discard the colostrums because they believe that it causes dysentery among the newborns. The urban slum mothers of Visakhapatnam (Swamy, 2009) discarded the colostrums due to the advice of elderly women of the family, or of traditional belief and consider colostrums as impure substances. Nearly $41.5 \%$ of the tribal mothers of Visakhapatnam district (Sambasiva Rao, 2008a) felt that the colostrums were not good for the health of child, traditional belief and even the elders also advised them to discard the colostrums. The other reasons reported by them are that the colostrums were stagnant, not pure, heavy to digest and look like pus. The Bhumija tribal women of Orissa also reported the reasons for discarding the colostrums, the reasons are- unhygienic, undigestible, very thick (viscous), cheesy and not good for the baby.

The practice of offering pre-lacteals to the newborns are more in Gadaba (27.3\%) than the Konda Dora tribe $(22.7 \%)$ whether the initiation of breast milk to the newborns are delayed or not (Table-2). Usually many babies are fed with pre-lacteal foods. The data reveals that out of 357 newborns that were initiated with breast milk with in 1 hour after birth 10 of them (2.8\%) were given pre-lacteal foods. Similarly in the subsequent intervals of delay in the initiation of breast milk, the percentage of newborns given pre-lacteals are gradually increased from $38.5 \%$ to $100.0 \%$. In total, $25.0 \%$ of the newborns belong to both the communities were offered with pre-lacteal foods of different varieties. The most commonly offered pre-lacteal food is sugar water/sugar candy water among Gadaba (47.5\%) and Konda Doras (58.8\%). The next option of pre-lacteal is castor oil $(37.7 \%)$ among Gadaba and Konda Doras (20.5\%). The other pre-lacteals are honey (8.0), other mother's (surrogate) breast milk (5.3\%) and packet milk (4.0\%) (Fig-2).

The practice of pre-lacteal feeding is still predominant in both Gadaba and Konda Dora tribal newborns, mostly among the babies where initiation of breast milk was delayed and also among the newborns who were initiated mothers' milk even before 6 hours after birth. It indicates their strong traditional belief which adhere them to the practice of discarding colostrums before the initiation of breast milk. Pre-lacteal feeding also varies substantially from one community to another in all states of India. The practice of offering pre-lacteal feeds to the newborns is at minimal level in the states of Kerala (10.8\%), Sikkim (12.3\%) and Arunachal Pradesh (16.7\%). The Pre-lacteal feeding is most common in Bihar (90.6\%), Uttar Pradesh (86.0\%), Rajasthan $(71.6 \%)$ and Jharkhand (66.3\%) NFHS-3 (2005-06). The mothers from the urban slums of Indore (Aggarwal, 
et.al., 2007) feed their newborns with jaggery water or tea or honey or un-boiled water or goat/ cow milk or a traditional 'ghutti' made from honey and nutmeg. However, a study conducted by Yadav, et.al., (2007) on traditional practices in newborn care of Nepal shows that colostrums was regarded as dirty milk in some communities and babies were fed with cow or goat milk immediately after birth for the popular belief that it will make the baby become more intelligent.

Majority of the Gadaba and Konda Dora tribal mothers offered either sugar water or sugar candy water or castor oil or honey or surrogate breast milk or pasteurized (commercially available) milk. In developing countries, it is often argue that separation of the newborn from mother and feeding the newborn with mothers' milk substitutes during the first day of the birth is an important factor responsible for failure of lactation.

As per the experts' advice, giving pre-lacteals in any community is considered as an unhealthy practice because the first breast milk of the mother is the best food for the newborns. The method of feeding the prelacteals involves many unhygienic practices. In the present study populations, they dip the cotton in the prelacteal items (sugar water/ castor oil/ honey/ pasteurized milk) and squeeze the food item in the mouth of newborn with the help of their fingers (Gadaba-36.3\% and Konda Dora- 14.9\%) and by using unsterilized table spoon (Gadaba-35.0\% and Konda dora-56.7\%). They use the cotton as the tool for giving the pre-lacteals (Gadaba-20.0\% and Konda Dora- 10.4\%), bottle (Gadaba - 3.8\% and Konda Dora- 14.9\%), used rubber teat (3.8\% in Gadaba and 3.0\% in Konda Dora) and also uggu ginne (traditional bowl)very rarely (Gadaba-1.3\%).

Not only the pre-lacteal foods but also the method of offering the pre-lacteals to the newborns needs some attention to validate the practice as good or bad. In majority of the situations, the mothers are using either finger or the unsterilized spoon or cotton rag or rubber teat or uggu ginne (traditional bowl) to give pre-lacteal feedings. And all these were observed as most unhygienic which leads to the health complications especially diarrhoeal diseases among the newborns. These observations made in the present study show the affinity with some of the ORG studies undertaken in Baroda slums (Khan, 1990) as well as in the rural areas of Gujarat (ORG, 1989) and those undertaken by the Nutrition Foundation of India in Maharashtra and West Bengal (Gopujkar, et.al., 1984). The use of a spoon for pre-lacteal feeding was quite common not only in Andhra Pradesh but also found in Maharashtra and West Bengal.

IV. FIGURES AND TABLES

Table-1: The practice of discarding the colostrums and the reasons behind it.

\begin{tabular}{|c|c|c|c|c|c|c|}
\hline \multirow{2}{*}{ Colostrums } & \multicolumn{2}{|l|}{ Gadaba } & \multicolumn{2}{|c|}{ Konda Dora } & \multicolumn{2}{|l|}{ Total } \\
\hline & Number & $\%$ & Number & $\%$ & Number & $\%$ \\
\hline Discarded & 77 & 25.7 & 60 & 20.0 & 137 & 22.8 \\
\hline Not discarded & 223 & 74.3 & 240 & 80.0 & 463 & 77.2 \\
\hline Number of times discarded/day & & & & & & \\
\hline 1 & 24 & 31.2 & 25 & 41.7 & 49 & 35.8 \\
\hline 2 & 30 & 39.0 & 16 & 26.7 & 46 & 33.6 \\
\hline 3 & 22 & 28.6 & 16 & 28.3 & 39 & 28.5 \\
\hline$>3$ & 1 & 1.3 & 2 & 3.3 & 3 & 2.2 \\
\hline Reasons for discarding & & & & & & \\
\hline Stagnant & 1 & 1.3 & 2 & 3.4 & 3 & 2.2 \\
\hline Heavy to digest & 2 & 2.6 & - & - & 2 & 1.5 \\
\hline Not good for child & 23 & 38.5 & 22 & 37.9 & 52 & 38.2 \\
\hline Not pure & 5 & 6.4 & 6 & 10.3 & 11 & 8.1 \\
\hline Traditional belief & 15 & 19.2 & 14 & 24.1 & 29 & 21.3 \\
\hline Advice of elders & 25 & 32.1 & 14 & 24.1 & 39 & 28.7 \\
\hline
\end{tabular}

Table-2: The type of pre-lacteals offered to the newborns by the tribal mothers

\begin{tabular}{|l|l|l|l|l|l|l|}
\hline \multirow{2}{*}{ Variable } & \multicolumn{2}{|l|}{ Gadaba } & \multicolumn{2}{l|}{ Konda Dora } & \multicolumn{2}{l|}{ Total } \\
\cline { 2 - 7 } & Number & \% & Number & \% & Number & \% \\
\hline Pre-lacteals given & 82 & 27.3 & 68 & 22.7 & 150 & 25.0 \\
Not given & 218 & 72.7 & 232 & 77.3 & 450 & 75.0 \\
Pre- lacteal items & & & & & & \\
Sugar water/sugar candy water & 39 & 47.5 & 40 & 58.8 & 79 & 52.6 \\
Honey & & & & & & \\
Other mother's breast milk & 6 & 7.3 & 6 & 8.8 & 12 & 8.0 \\
Castor oil & 4 & 4.9 & 4 & 5.9 & 8 & 5.3 \\
Pasteurized milk & 31 & 37.7 & 14 & 20.5 & 45 & 30.1 \\
& 2 & 2.4 & 4 & 5.9 & 6 & 4.0 \\
\hline
\end{tabular}


Practices Regarding Colostrums and Pre-Lacteals among Gadaba...

\begin{tabular}{|l|l|l|l|l|l|l|}
\hline \multirow{2}{*}{ Variable } & \multicolumn{2}{|l|}{ Gadaba } & \multicolumn{2}{l|}{ Konda Dora } & \multicolumn{2}{l|}{ Total } \\
\cline { 2 - 7 } & Number & \% & Number & $\%$ & Number & $\%$ \\
\hline Materials used to feed & & & & & & \\
Spoon & 28 & 35.0 & 38 & 56.7 & 66 & 44.9 \\
Bottle & 3 & 3.8 & 10 & 14.9 & 13 & 8.8 \\
Cotton & 16 & 20.0 & 7 & 10.4 & 23 & 15.6 \\
Finger & 29 & 36.3 & 10 & 14.9 & 39 & 26.5 \\
Rubber teat & 3 & 3.8 & 2 & 3.0 & 5 & 3.4 \\
Uggu ginne (a kind of bowl) & 1 & 1.3 & - & - & 1 & 0.7 \\
& & & & & & \\
\hline
\end{tabular}

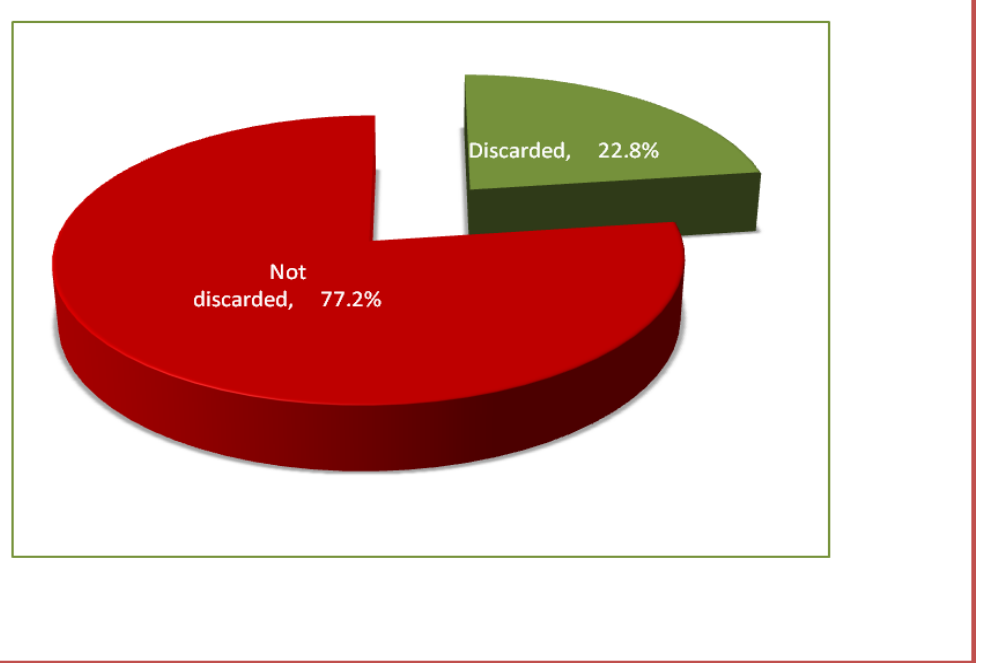

Fig No: 1 Discarding of colostrums among the tribes

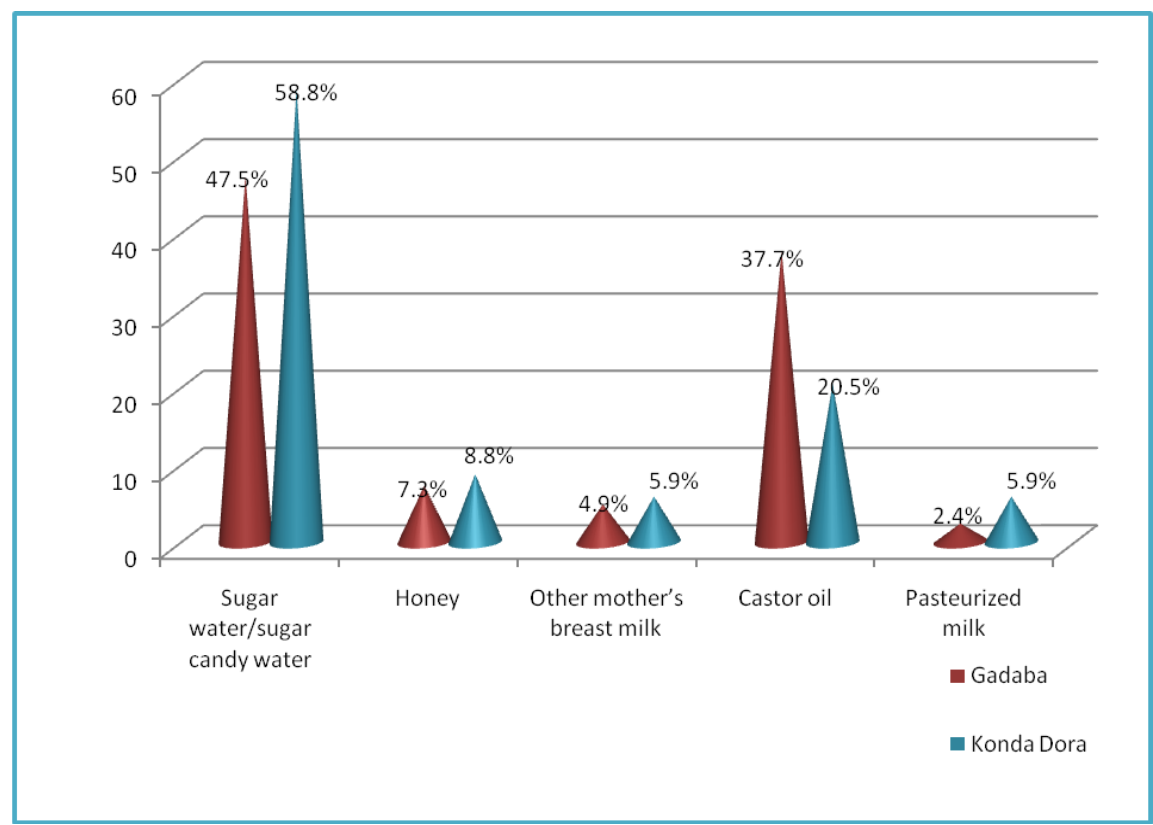

Fig No: 2 The type of pre-lacteal items offered to the newborns by the tribal mothers

\section{CONCLUSION}

The practice of discarding of colostrums (the first breast milk) is still exists among Gadaba (25.7\%) than Konda Dora $(20.0 \%)$. About $64.0 \%$ of women from both the tribes have discarded the colostrums about twice or more than 2 times They are discarding the colostrums mostly because of elders' advice and also 
believed that the milk may not good for child, and consider it as impure and have strong traditional belief. Because of the late initiation of the breast milk, the newborns were fed with pre-lacteal foods ( $27.3 \%$ of Gadaba and $22.7 \%$ of Konda Dora newborns). Sugar candy water, castor oil, honey, surrogate mothers' breast milk and pasteurized milk are the common pre-lacteal foods offering to the newborns in both these communities. They are feeding the newborns with pre-lacteals in a most unhygienic method i.e. by using either finger or spoon or cotton. The present Gadaba and Konda Dora population is relatively better in practicing the early initiation of breast feeding and maintaining the normal span of exclusive breast feeding. The discarding of colostrums by the present respondents is also relatively low when compared to the other tribal population's studies so far.

\section{ACKNOWLEDGEMENTS}

The co-operation extended by the Gadaba and Konda Dora people during the filed study, knowing not the purpose of it, gives a special dedication and mention here with a deep sense of gratitude.

\section{REFERENCES}

[1] Agarwal P, Singh MM, Garg S. (2007). Maternal health-care utilization among women in an urban slum in Delhi. Indian J Community Med;32:203-5

[2] Banerjee Sainath and Tanvi Mishra, (2006). Some post delivery practices. Solution Exchange for the Maternal and Child Health Community, Consolidated Reply .Query: Analyzing traditional birthing practices, from WHO India (experiences). Compiled by Meghendra Banerjee, resource person; additional research provided by Syed shahid abbas, research associate.

[3] Durga Rao. P., Sudhakar Babu. M., Narasimha Rao. V.L., 2006. Persistent traditional practices among the tribals of North Coastal Andhra, Stud. "Tribes and Tribals", 4(1): 53-56.

[4] Gopaldas T and Gujral S, (1995). Girl child environment. Social Change, No: $2 \& 3$.

[5] Gopujkar, P.V., Chaudhari, S.N., Ramaswami, M.A., Kore, M.S. and Gopalan, C. (1984). 'Infant Feeding Practices with Special Reference to the Use of Commercial Infant Foods'. Nutrition Foundation of India.

[6] Goswamy Monali, (2009). Reproductive Health and Fertility regulation of the Bhumija tribe of Balasore, Orissa, Thesis submitted to the degee of doctor of Philosophy to Post graduate department of population studies, Fakir Mohan University, Balasore, Orissa.Hemalatha, 2005

[7] KarenM.Edmond. CharlesZandoh., Maria A. Quigley., SeebaAmenga-Etego., Seth Owusu-Agyei and Betty R. Kirkwood. (2006).Delayed Breastfeeding Initiation Increases Risk of Neonatal Mortality, Pediatrics, 117,pp380-86.

[8] Khan, M.E. and Basu, J.K. (1987). Breast-feeding Among Working Women in Organized and Unorganized Sector, Report submitted to ICMR, New Delhi, ORG, Baroda.

[9] Khan, M.E. (1990). Breast - feeding and Weaning Practices in India. Asia. Pac. Popul. J., 5(1): 71-88.

[10] Mudgal S, Raijput VJ, Chansoria M and Kaul KK, (1979). Tribals of Madhya Pradesh: Knowledge, Attitude and Parctice survey of infant feeding practices. Indian Pediatrics. Vol 16(7): pp:617-622.

[11] Nanibabu, P., Sri Virajarani, J., Sambasiva Rao, R. and Hemalatha, M. (2006). Effect of breast - feeding on the health status of children and their mothers. Abstract. National Workshop on Health Problems and Health Care Systems among the tribes of India. Visakhapatnam: Andhra University, P.44.

[12] Narahari S, Narasinga Rao M, S. Bhaskara Babu and A. Aparna, (2009). The Porja: A Study on Pediatric Practices. Kamla-Raj, Anthropologist, 11(2): 147-149.

[13] NFHS-2 (1998-1999), Andhra Pradesh: International Institute for Population Sciences (IIPS) and ORC Macro (2000a). National Family Health Survey (NFHS-2), India, Andhra Pradesh, Mumbai: IIPS.

[14] NFHS-3 (2005-2006): International Institute for Population Sciences (IIPS) and Macro International. (2007). National Family Health Survey (NFHS-3), India, Volume 1. Mumbai: IIPS)

[15] ORG, (1989). 'Linkages between Women's Work and Child Development'. Operations Research Group. Baroda.

[16] Pandey GD and Goel AK, (1999). Some demographic characteristics of Abujhmaria of Madhya Pardesh. Journal of Humna Ecology, 20(2):85-88.

[17] Sambasiva Rao, R. (2008). Knowledge, Attitude and Practices (KAP) regarding RCH care among the tribes of Vizianagaram Distrcit- a situational analysis, A report submitted to Tribal Cultural Research and Training Institute, Hyderabad, (unpublished).

[18] Sambasiva Rao, R. (2008a). Child care practices among slum dwellers and tribal communities of Visakhapatnam. A report submiited to UNICEF, Hyderabad (unpublished).

[19] Swamy K.B. (2009). Infant Feeding practices among the slum dwellers of Visakhapatnam city, Andhra Pradesh, unpublished Thesis, Department of Anthropology, Andhra University, Visakhapatnam.

[20] United Nations Children's Fund Web site. The Baby-friendly Hospital Initiative: Revised and updated materials 2006. Available from: http://www.unicef.org/nutrition/index_24850.html [Last accessed on 2008 Apr 29]. `

[21] UNICEF, (2011). Programme guide on Infant and young child feeding. Nutrition section, UNICEF programmes, UNICEF, New York.

[22] Yadav. R, Agrawal M. C., Rao V. G., Vohra S., Bhondeley M. K., Ukey M. J., Anvikar A. R., (2007). Is Active Human Schistosomiasis Present in India? Current Science, 92(7): 889. 